\title{
Ideal Types-Theoretical Models as Agent of Transformation Towards Sustainability
}

This chapter introduces the ideal types of a transformative policy pathway as the agencies of transformation: democratic, authoritarian, institutional, activistic, technocratic or bureaucratic, and post-democratic. Functioning as 'corridors' where transformation is facilitated, each of these ideal types of policy models may have distinct preferences regarding procedures of collective decision-making. These procedures are, for example, highly dependent upon existing path dependencies defined by how each ideal type tends to draw legitimacy in front of its audience.

A major purpose of this chapter is to 'unmask' the normative judgment of policy models, whereas the academic literature on transformation for example tends to link environmentalism with democratic governance (see Humphrey 2007). While democratic and authoritarian ideal types of policy pathways reflect the types of regime, institutional, activistic, technocratic and post-democratic ideal types of policy pathways can be considered as deviations, because they can be found in both democratic and authoritarian regimes. The separate analysis of these 'subtypes', or deviations, are significant as they suggest different dynamics in the transformation process, which will be illustrated through the integrated streams of transformation. 


\subsection{An Ideal Type of Transformation-The Democratic Policy Pathway}

The ideal type of a democratic policy pathway pertains to a 'corridor' or a 'transformation roadmap' that identifies the multiple underlying stages, paces, episodes or parts of orchestrated transformation and the various conflict cleavages within a specific stage or episode. As figure 8.1 suggests, this integrated stream illustration identifies the relevant stakeholders for each stage and episode, whose interactions produce a collection of outcomes (both agreements and non-agreements). These interactions lead to the concretization and elaboration of the relevant issues and interests involved, allowing the integrated understanding of barriers into the transformation and eventually establishing possible procedures of resolution (Fig. 8.1).

Each box of the diagram represents a sub-system where various types of negotiations occur. Each of these subsystems have distinct actors, issues/agendas, processes, structures, and outcomes. Furthermore, the relationship between these inter-related subsystems may be complementary or competing. The different phases of negotiation - the opening of the process, agenda setting, the clarification of interests, generating solutions and ending the process-are reflected in the diagram (see Zartman 1978; Young 1991; Sebenius 1992b), suggesting the incremental nature of the transformation process. 


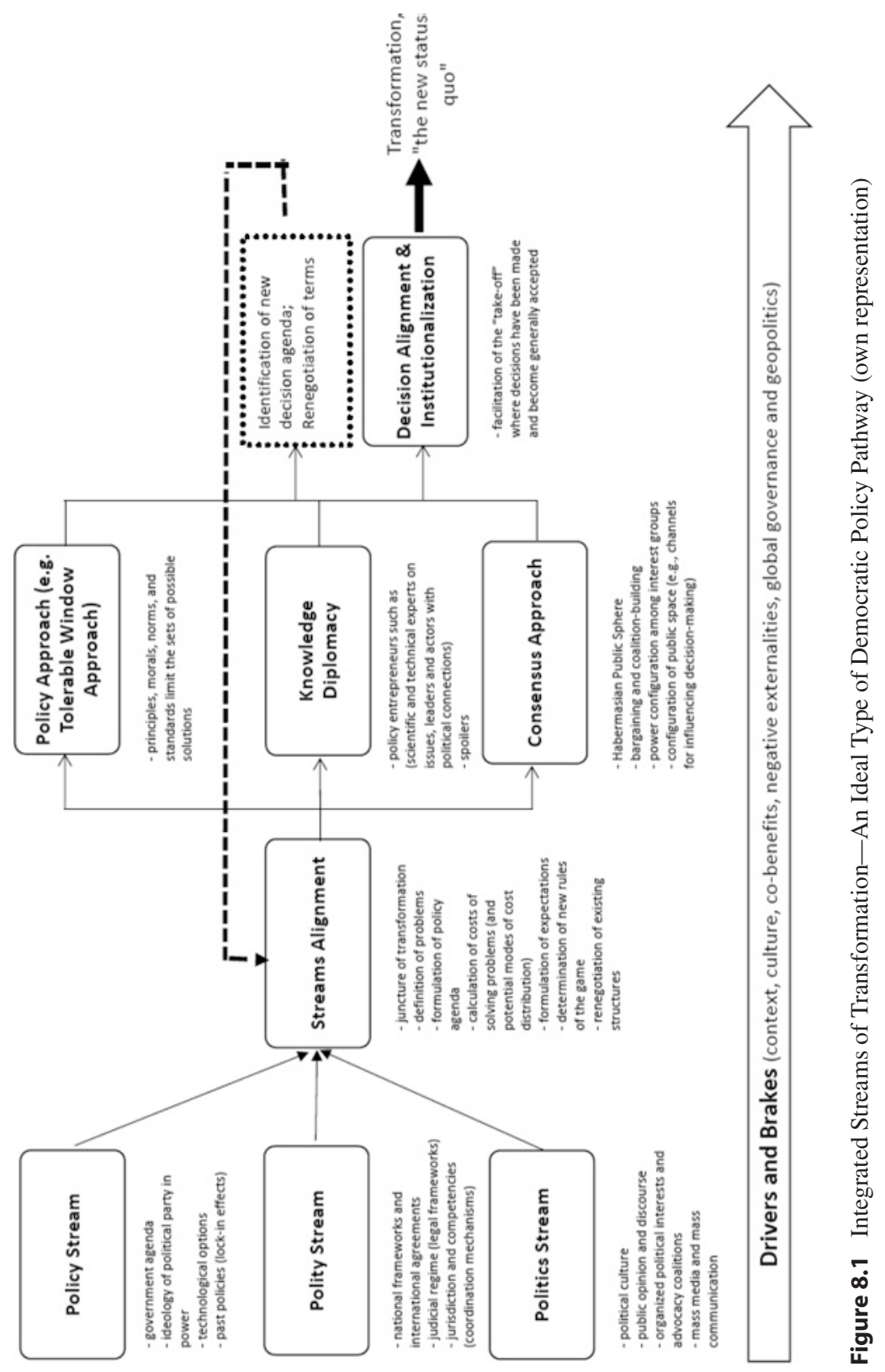




\subsubsection{Context: Actors and Issues}

Because the competitive advantage of political actors in democratic countries is defined by how they manage to align their political interests with public opinion or how they shape public opinion, bargaining interactions are important subjects of analysis in democratic pathways. In many cases, public opinion is not defined by a 'collective logic,' but by how arguments are made, communicated and exchanged. Moreover, public opinion is often heterogeneous and, in some cases, fragmented, as many societal groups with complementing and competing interests seek to claim representation of what 'society wants.' In some countries, universities and other academic institutions play a significant role in providing a 'public space' where various societal groups can meet and exchange perspectives.

The diagram highlights the role of drivers and brakes in either promoting or delaying the various negotiation processes. These drivers and brakes are frequently path-dependent, which can be properly addressed when transition costs are comprehensively identified and accommodated. Context, for example, is an important factor that needs to be discussed. It explains the occurrence of a decision in one setting while being unimaginable in a different setting. The Fukushima incident has, for example, led to policy shifts in Germany, yet not in other countries.

This illustration summarizes the different channels where a transformation process can be initiated: policy, polity and politics streams. Like in the first phase of negotiation, the left side of the diagram pertains to how transformation is initiated by the emergence of a specific challenge, which can only be addressed when changes occur. The policy stream refers to government agenda as significantly defined by the ideological preferences of the political party in power, the technological options available to implement policies, viable alternatives and the related costs of pursuing these alternative opportunities, and the locked-in policies that were made in the past. For example, a government may initiate new policies to implement electoral promises. However, the fulfilment of electoral promises may be dependent on how much change the constitution allows (e.g., Rückwirkungsverbot, or the principle of non-retroactivity in Germany).

In addition, a government may revise existing policies, for example, to adhere to international or regional agreements pertaining to climate mitigation measures. Although international agreements may contrast with a government's formal position, for example, in terms of climate mitigation, because expected gains will serve other, highly-prioritized political goals, the country opts for cooperation. For example, Poland and the Czech Republic, countries that are highly dependent upon coal energy and are staunch opponents of ambitious mitigation measures that relate to coal energy, have agreed to commit to more stringent climate 
protection policies to fulfil the agreements they have agreed to upon their ascension to the European Union (Darby 2014). Moreover, a reversal of past policies may be a product of crises and even of natural disasters.

The polity stream pertains to the national institutions in place. It includes the institutions responsible for monitoring, evaluating and verifying government actions. The politics stream is dynamic and is defined by the power relations between actors, as well as how existing polities serve as formal and material frameworks that allows weaker parties to cope with asymmetrical relations. The polities will then review if new policies are in accordance with the existing rules of the game while evaluating the resilience of the system. In most countries, new government policies most likely result in legal challenges from various sectors of the society. This possibility of check-and-balance promotes social trust; as weaker actors are assured that they have access to formal channels of decision-making.

Politics is the stream that refers to how public discourse will unfold and the various complementing and competing perspectives regarding concrete matters are mobilized and communicated. This stream also involves the expression of power games, as the societal actor that has most of the relevant effective resources will tend to dominate the discourse. Power resources do not only refer to money, but also to information, including how information is disseminated. For example, an environmental group with fewer financial resources could find more public support if it could present a more compelling argument based on scientific facts or at least the impression of serious evidence.

\subsubsection{Agencies: Structures and Processes}

The alignment of the three streams is a significant part of the transformation process, because it represents the critical juncture that determines subsequent steps. For example, as the policy stream identifies energy security as a political priority and agenda, the politics stream may agree on the importance of resolving threats to energy security especially when these threats to energy supply are causing higher energy prices. At this point, the polity stream may not have major reservations except when huge interventions are to be made by the state in the energy market that could reach the tipping point. In the streams-alignment stage, all the issues behind energy security will be collected and translated into the respective language of the different streams.

After the agreement on the agenda, the streams-alignment is followed by the identification of a mixture of approaches through which various interests are processed and evaluated. The process unfolds, leading to the combination of three 
possible approaches, where one approach can be more dominant than the others, depending on the importance of the issues involved. The policy approach involves the normative setting provided by past and present policies. While the government may set the limits of what is politically acceptable, for example, the same national government needs to adhere to these limits. It may define that changes in the country's energy system should not undermine the global competitiveness of the country. This normative setting may subsequently limit the financial burdens of transitions and legitimize financial incentives or tax exemptions to business and industrial companies affected by transition.

From the policy-approach perspective, the resolution of an issue needs to be within the boundaries set by pre-defined guard-rails that exclude the intolerable impacts of an emerging problem as well as any unacceptable measures used to address and resolve these problems. These guard-rails will eventually define and frame institutional interactions, in which certain policy principles need to be considered, no matter what policy area is involved. Such guard-rails can be directly defined by polities (e.g., the constitution) or be directly negotiated ad hoc by relevant actors determining principles that frame subsequent actions. For example, the "tolerable window" may include provisions for the protection of human rights, especially for indigenous communities.

\subsubsection{Audience: Outcomes}

The three approaches - the policy approach, knowledge diplomacy and the public consensus approach - interact in various forms by complementing, substituting or competing. The three approaches will eventually define the new social contract. In cases of stalemate, new agendas may be introduced, paving the way for new rounds of negotiations. Subsequently, decisions are achieved by following the conclusions of 'follow-up' negotiations. When decisions are then implemented, they call for the institutionalization of practices. Eventually, institutionalization will lead to new status quo and transformation that has followed a democratic policy pathway will have been completed.

\subsection{An Ideal Type of Transformation-The Authoritarian Policy Pathway}

Academic debate around environmentalism, particularly when addressing climate change, is increasingly focusing on the significance of the types of governance or regimes as agents of transformation towards sustainability (see Newig 
\& Fritsch 2009; Young 2009; Zelli 2011). For example, Derk Loorbach (2010) introduces transition management as a new governance approach for sustainable development. He highlights the impact of the long-term outlook on network and decision-making processes. While the definition of authoritarianism has become less contested in the last few decades (see Avritzer 1995; Altemeyer 2006), there is an emerging debate as to how authoritarianism relates to environmental policies. Mark Beeson (2010) argues that the intensification of a range of environmental problems reinforces authoritarian regimes, particularly in East Asia and Southeast Asia. To understand this presumed linkage between environmentalism and authoritarianism, the value of this policy model as an agent for sustainable, low-carbon development needs to be determined. Following Juan Linz's (2007; 2009) three major indicators of authoritarianism (the de-politicization of society, limited pluralism and a connection to a traditional mentality), this section focuses on how (environmental) policy-making in authoritarian regimes facilitates transformation towards sustainability.

In light of the various challenges that hinder effective and efficient climate policy formulation and implementation, arguments have been raised about the incapacity of democratic regimes to effectively respond to climate problems. A growing literature on 'authoritarian environmentalism' or 'ecological authoritarianism' has emerged, proposing a non-participatory approach to public policy-making and implementation to address environmental challenges such as climate change (see Doyle \& Simpson 2006; Beeson 2010; Gilley 2012). On the one hand, how democratic countries can isolate environmental policies from other policy areas and purposely 'suspend' or 'limit' civil rights and liberties for climate protection is discussed (see Heilbroner 1974; Beeson 2010). On the other hand, several experts have focused on how stable authoritarian regimes can effectively respond to environmental challenges (Sowers 2007; Schreurs 2011). For example, the Chinese case study of Bruce Gilley (2012) provides a comprehensive analysis of how authoritarian environmentalism is practiced in China.

\subsubsection{Challenges to Developing an Ideal Type of an Authoritarian Policy Pathway}

In conceptualizing an ideal type of an authoritarian policy pathway, there are several challenges that need to be clarified. One significant challenge refers to the current diversity of existing authoritarian regimes. This diversity complicates the potential representativeness of this ideal type. There are different 
types of authoritarian regimes and these types can become even more complex and intangible when local cultural aspects enter the spectrum of analysis. For example, after differentiating authoritarianism from democracy as well as from totalitarianism, Juan Linz $(2007 ; 2009)$ differentiates seven subtypes of authoritarian regimes: (1) bureaucratic-military; (2) corporatist; (3) mobilizing regimes in post-democratic states; (4) post-colonial; (5) racial and ethnic 'democracies'; (6) incomplete totalitarian and pre-totalitarian; and (7) post-totalitarian. Other authors have also introduced different subtypes of authoritarian regimes. While Wolfgang Merkel (1999) bases his subtypes on the holder of power (Herrschaftsträger), Armin Pfahl-Traughber (2004) defines the subtypes according to the legitimacy of authority. This book introduces an ideal type of an authoritarian (environmental) policy pathway that focuses on interactions between actors and institutions as results of the interplay between agents, agencies and audience.

Another challenge refers to the lack of a clear separation between authoritarian and democratic regimes. While there is common knowledge about how authoritarian regimes are to be distinguished from democratic regimes, certain democratic elements can still be observed in authoritarian regimes in the same manner as authoritarian tendencies can be identified even in the purportedly most democratic regimes. Because of this, it is difficult to clearly attribute environmentalism either to the democratic elements of an authoritarian regime or to the authoritarian elements of a democratic regime. Furthermore, democratic regimes may prefer authoritarian procedures when addressing specific issues, especially issues that can stir social division. In addition, constitutions of most democratic countries have provisions allowing limitations to political pluralism such as the implementation of martial law and the suspension of habeas corpus under specific conditions that can be easily 'abused' for other political reasons. Facing increased political opposition and the loss of political power, political leaders can "stage" different types of crises. Minor crises can be projected out of proportion for political gains. Moreover, as Bob Altemeyer (2006), a leading scholar on authoritarianism argues, a simple but significant majority can be mobilized to democratically elect a charismatic leader. He suggests that as time passes, the drive for authoritarianism may become stronger as this leader may see the need to suppress opposition to fulfil electoral promises. With the majority's support or with the passiveness (or ignorance) of the silent majority, democratic regimes can feel authoritarian, given their mandate to limit political liberties, for example those of minorities, and to suppress political opponents who can be easily cast as risks and threats to the stability of the system. 


\subsubsection{Advocacy, Social Movements and Authoritarian Environmentalism}

A growing number of researchers are analyzing the role of social movements including NGOs in authoritarian states and many of them see environmental advocacy as a type often tolerated by these states (Sowers 2007; Mertha 2009). Especially because environmental groups tend to pursue interests that coincide with state policies of restricting rights and liberties of other actors such as business and industry, authoritarian regimes see their benefits when seeking inhibitions to the rule of law that will exclude corporate and business actors as well as other groups from participation in policy processes on the basis that they are mostly opposed to environmental action or that their existence is leading to environmental degradation (see Shearman \& Smith 2007; Wells 2007; Gilley 2012). For example, while public policy processes in China are non-participatory, public policies involving environmental issues including air pollution or climate change have indeed engaged in an advanced level of societal participation (Gilley 2012). Nevertheless, broader public participation in environment-related public policies in China is limited to cooperation with state authorities (see Teng \& Gu 2007; Lei 2009).

In response to the existing difficulties in forging agreements to effectively address the environmental challenges brought about by climate change, there is a growing literature calling for alternative public policy models. This growing literature often refers to the effectiveness of authoritarian policy models in confronting environmental problems. As the case study on the Philippines demonstrates, because the successful implementation of measures that would ensure environmental integrity implies restrictions, and because of civil society activism around environmental issues, there is an increasing preference towards authoritarian structures within democratic states (see Sowers 2007; Beeson 2010; Geronimo 2016; Pora 2017).

Most of the academic studies on authoritarian environmentalism address this policy model in comparison with democratic environmentalism. Many scholars argue that authoritarian environmentalism is more effective than democratic environmentalism in addressing the specific characteristics of environmental issues, including public ignorance, public irrationality, free-riding, the need for immediate action, the lack of resources to motivate social action and multi-stakeholder veto players (see Diehl \& Gltsch 2001; Barrett 2003; Posner 2004; Arias-Maldonado 2007; Stone 2009; Beeson 2010; Gilley 2012). Authoritarian environmentalism refers to the concentration of state authority in executive institutions, which facilitates a rapid formulation and implementation of environmental 
policies through limitations on individual freedoms and the partial or total exclusion of social actors or their representatives (see Shearman \& Smith 2007; Sowers 2007; Beeson 2010).

In comparison, democratic environmentalism pertains to a public policy model that spreads authority across several levels and agencies of government and where direct public participation from various groups of society is encouraged, if not guaranteed (see Holden 2002; Humphrey 2007; Gilley 2012). Participation takes place from the upstream stage (research and knowledge formation, problem identification, measurement and assessment, policy options identification and assessment) to the midstream stage (policy selection and formulation) to the downstream stage (policy implementation, leadership, monitoring, reporting, assessment and revision) (Birkeland 2005). In addition, participation occurs at different levels: low level (being targets of state propaganda, reporting public violations and attending informational meetings) and high level (legally-binding and deliberative forums, outright citizen autonomy, legislative sovereignty) (see Arnstein 1969; Plummer \& Taylor 2004; Gilley 2012).

While authoritarian environmentalism is able to produce a rapid and centralized response to environmental threats and mobilize much needed public support, the society will most likely not always benefit from the outcomes of such policies, because of other emerging problems caused by the exclusion of key stakeholders in policy-making. Especially in many developing countries with weak governance and a highly fragmented society, the benefits of authoritarian environmentalism will more likely not contribute to sustainable development due to the authoritarian system's proneness to favoritism towards technocratic elites (see Shearman \& Smith 2007). Looking at China, which is regarded as a positive example of the effectiveness of authoritarian environmentalism, opponents argue that the authoritarian model is causing poor policy formulation and poor policy implementation (Gilley 2012). Before summarizing the parameters of this ideal type, there is a need to clarify that this ideal type presupposes an authoritarian regime with continual stability and robustness, that is, an authoritarian regime that is deeply embedded in the society and in the culture of that specific country. The cultural integration of authoritarian rule is expressed through narratives and a psychological disposition of the constituents which are enforced by social institutions (see Adorno et al. 1950). Furthermore, there is a significant amount of the (formal) rule of law in such a regime that allows a degree of predictability of policies and political actions.

Figure 8.2 is the illustration of an authoritarian policy pathway that summarizes the steps typically taken as the process of policy formulation and implementation unfolds. 


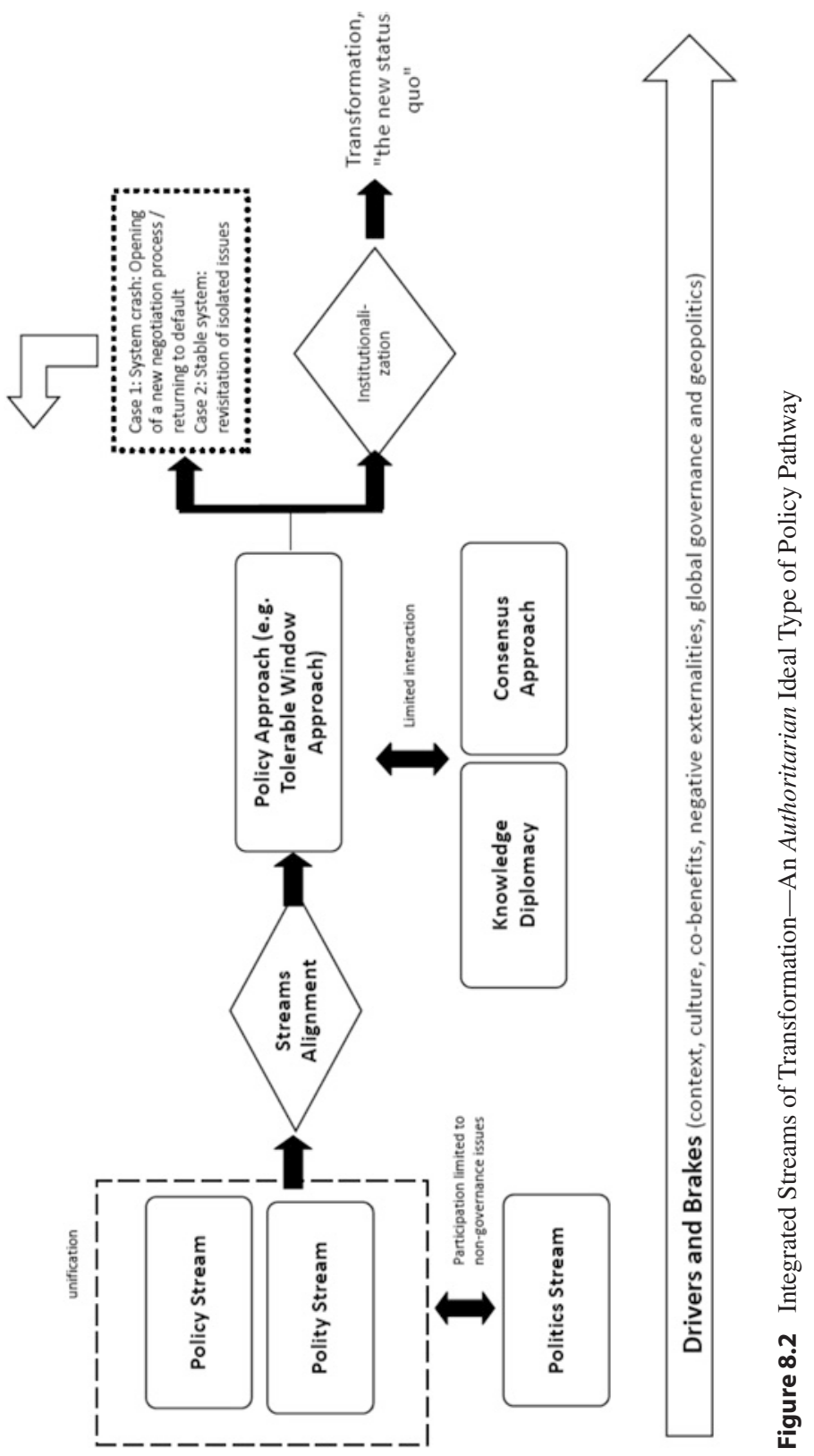




\subsubsection{Context: Actors and Issues}

In an authoritarian policy pathway, (political) elites such as agents from the policy and polity streams historically dominate policy-making. This dominance is guided by socio-technical and socio-linguistic narratives that legitimate the control of state institutions. The recruitment of new members of the elite is structured and to a certain degree eidetic. Depending on the subtype of the authoritarian regimes, who will be in the next generation of leaders is most likely predictable. While from a normative perspective, the recruitment process is unjust and inequitable, this predictability of recruitment can ensure long-term stability as power is passed from one generation to another. For example, because a military regime will most likely involve military personnel in higher political positions, citizens who aim to hold political offices will need to enter the military and pursue a military career. In racial and ethnic 'democracies' (e.g., Apartheid South Africa), belonging to the ruling racial or ethnic group ensures access to political offices.

Nevertheless, the participation of the politics stream (civic society groups and those groups excluded from the political elite) is still possible or in some cases even encouraged. Compared to democracies, the consensus approach involves a different process in authoritarian regimes. Social movements are not dormant in this ideal type of authoritarian policy pathway, but rather stratified. Participation in social movements is limited to certain domains or issues and is 'tolerated' as long as it does not pose an opposition to certain state policies and to the political system in general. A social group can achieve 'non-threat' status when it has, for example, existing, informal connections with members of the political elites or when social networks are seen as beneficial to the legitimacy of the regime. Such informal connections often imply the personal guarantees of members of the ruling elite. In various cases, authoritarian regimes are keen to work with social movements as these can serve as pools of new recruits. Furthermore, the interaction between policy-makers and scientific communities often involves scientific and technocratic elites with long-standing relationships with the state. Knowledge diplomacy takes place in a rather controlled manner. In 'stable' authoritarian states, state universities and other research institutions are directly or indirectly managed or funded by government agencies. Therefore, scientific knowledge can easily be 'institutionalized' and interpreted in a way that supports government policies.

In stable authoritarian regimes like China and the United Arab Emirates, climate protection measures are most likely decoupled from political opposition. This is done by framing climate protection as an integral part of social policies that are concerned with human well-being. Embedded in existing social policies, climate protection becomes an indicator of output legitimacy through performance. Therefore, the regime will most likely allow more ambitious targets. 
Authoritarian regimes that are able to achieve higher indicators of welfare are more likely to receive adulation from the audience as compared with democratic states. In addition, because a failure to achieve ambitious targets will not face drastic criticism domestically as communication channels are controlled by the regime, authoritarian regimes are most likely willing to set ambitious targets. Furthermore, modernization is framed as an indicator of performance that legitimizes the authoritarian system of governance. Aware of the risks of modernization to the system, stable authoritarian regimes have found ways to expand the benefits of modernization to a larger part of the population, thus, promoting social cohesion. This 'guided' modernization proves to be more effective than the use of violence.

\subsubsection{Agency: Structures and Processes}

Because the stable authoritarian regime derives its (output) legitimacy primarily from its performance in achieving indicators of modernization, bureaucracies of authoritarian regimes will most likely play a very significant role in planning. Stream alignment is rather simple, because state authority is concentrated in executive institutions. Decisions are expected to be swifter and policies tend to be predictable, as historically dominant policies will significantly influence the approach that policy-makers will take when addressing new areas. The characteristics of historical policies will be most likely reproduced in new policies. For example, in a country where an authoritarian regime has historically used generous welfare policies (e.g., United Arab Emirates) to uplift the well-being of its citizens to ensure its legitimacy, the regime will most likely apply similar principles to addressing other policy areas such as climate protection.

Although modernization is often argued as a threat to authoritarian rule, as modernization tends to 'balance' power among societal actors, it can also be used to legitimize authoritarian rule, particularly in highly paternalistic societies (see Kreisky 1979; 2008). Because of the authoritarian regimes' control of communication systems (e.g., censorship, state media), 'authoritarian culture' is enforced. When the authoritarian regime can effectively 'frame' the minds of citizens in terms of the meaning of ('guided') modernization, legitimacy is ensured.

Processes refer to various means of interactions that allow the achievement of decisions that advance the transformation process. As discussed above, although authoritarian countries are governed center-to-periphery and top-down, there is this predictability of institutional interactions (implying stability), as the character of historically dominant policies will define the policies adopted in new areas. Jurisdictions and hierarchies are well defined, implying a certain degree of accountability. 
In addition, authoritarian structures define functional interaction, where actual or potential interaction between policies can be emphasized. Policy approach will most likely be highly functional, as fewer stakeholders will be involved. The tolerable window approach is defined by historical policies and will most likely not be subjected and open to intense bargaining with non-state actors. Moreover, bargaining interactions in authoritarian countries are framed and managed by the authoritarian regime. While the regime will allow the significant information participation of social elites and mid-level social movements and activists, the boundaries are well clarified, and violations are heavily sanctioned. In addition, bargaining interactions between elites and other social actors in authoritarian policy pathways tend to occur through informal and non-public channels.

\subsubsection{Audience: Outcomes}

It is assumed in this ideal type that while policy outputs are more easily achieved, these outputs are highly contingent on system stability. Because all governance structures of authoritarian states are construed to ensure system stability with low or no tolerance to challenges to the system, not to mention state control of communication channels, it is most likely difficult to anticipate when a rupture will occur. Therefore, system ruptures in authoritarian states will most likely 'catch everyone in surprise.' However, in case there is a rupture and the authoritarian system collapses, system default will most likely occur, and the transformation process will most likely need to start from zero, which implies a high degree of uncertainty. Nevertheless, a system rupture occurring in a democratic state may also lead to previous policies being disregarded, but it is assumed that dispersed decision-making as a result of factional politics following the separation and distribution of powers among various levels will mostly likely allow these 'dispersed' policies to be maintained.

The learning process is very important for authoritarian regimes. It is assumed that stable authoritarian regimes can adapt quickly to new challenges as decision-making does not need to undergo a rigid political debate among various political groups. The government can adapt faster to new conditions. In addition, because authoritarian regimes will most likely influence all aspects of the transformation process, outcomes will then require cooperation with state authorities from various levels. In addition, outcomes will be more embedded in existing historical policies. Persuasion interactions in authoritarian regimes will most likely be framed already by historical policies as these policies will identify the logic of the authoritarian regime. 


\subsection{An Ideal Type of Transformation-Policy Pathways Driven by Institutional Activism}

In reality, democratic policy systems are often confronted with deviations. On the one hand, these deviations can be significant, but they cannot constitute another ideal type because of integral differences. On the other hand, these deviations still need to be 'isolated' to identify what is different in this scenario compared to an 'ideal' democratic system, and to analyze how deviations lead to changes in the structures and outcomes of decision-making processes. This section addresses a scenario that constitutes a subtype of the democratic policy ideal type-the institutional activist-driven policy model.

\subsubsection{Literature on Institutional Activism -When Activists Hold Power}

As Rebecca Abers and Luciana Tatagiba (2014) assert, most of the North American and European literature on social movements ignore the possibility that activists might work from inside government bureaucracy. The literature on new social movements highlights the need for civil society groups to maintain distance from the state, not only to ensure their credibility, but also their independence. Civil society groups, often formalized as non-government organizations, are expected to exert a significant degree of "self-limitation" (Cohen \& Arato 1992), especially because proximity between bureaucracy and civil society would limit the latter's democratizing and transformative potential (Abers \& Tatagiba 2014).

This theory is far from reality. While the majority of the academic literature looks at civil society groups as the consultants, contractors or partners of government agencies when implementing policies, it is not rare that governments hire activists due to their technical expertise and on-the-ground knowledge. However, as Federico Rossi and Marisa von Bülow (2015) suggest, the tasks of these activists are often limited to small-scale projects and they usually have to content themselves with making incremental changes while trying to maximize the effects of small actions such as a well-placed word in a decree or a training manual. Nevertheless, there are several cases of mobilized social movements which have successfully influenced or even dictated policy-making. For example, a whole generation in Germany were mobilized in the 1960s and 70s following a contentious public debate on nuclear energy leading to the establishment of the Green party. 


\subsubsection{Environmental Activism and Democracy}

Environmental activism is considered to be a significant force behind decision-making concerning environment-related issues (see Wapner 1996; Sutton 2000; Chasek 2006). In general, the academic literature on democracy sees activism as a major pillar of deliberative or discursive democracy, in which deliberation and consensus is central to decision-making (see Bessette 1980; Gutmann \& Thompson 2002; Dryzek 2010). In contrast to traditional democracy, deliberative democracy sees authentic deliberation and not merely voting as the primary source of the legitimacy of the system. The function of activism is to expand the base of public support as it goes beyond partisan politics (Goldberg 2013). Amy Gutmann and Dennis Thompson (2002) highlight the importance of the process, which not only guarantees fair terms of cooperation for all parties, but also the possibility of defection should the outcome of participation be proven to be non-reasonable.

The relation between state and civil society is traditionally adversary (see Tilly 1978, 1985), particularly when civil society groups emerge because of deficiencies in and failures of state instruments. Civil society groups are usually engaged in "collective challenges" to the political system (see Tarrow 1994). When the existing governance proves not to be receptive to the demands of civil society groups, these groups tend to resort to coercive means. In deliberative democracies, civil society groups act as participants in the consensus-building process, often identifying agendas and providing the technical expertise needed for the identification and implementation of solutions.

Environmental activism is regarded as the main driver of the inclusion of environmental issues in the political agenda (see Princen \& Finger 1994; Wapner 1996; Andresen \& Gulbrandsen 2003; Epstein 2005; Dong 2010). For example, Thomas Princen and Matthias Finger (1994) suggest that environmental NGOs challenge the traditional structure of politics, especially when states are reactive to various environmental crises, behaving both as independent negotiators and as agents of social learning. They continue that environmental activism identifies the political agenda by linking biophysical conditions to the political realm. However, environmental activism is to be differentiated from activism that pushes for other issues such as political liberties or gender equality. Civil society groups pushing for environmental integrity often enjoy more leeway, especially when their demands are in accordance with government policies and when these demands do not question governance structures (see Doyle \& Simpson A. 2006; Sowers 2007; Beeson 2010; Schreurs 2011; Gilley 2012). 


\subsubsection{Relations Between Activism and Climate Protection- The Scientific Community as Norm Entrepreneurs?}

Environmental activism is key to politicizing environmental issues and to bringing them to the political sphere not only at a national but also at a global level. Paul Wapner (1996) acknowledges that transnational groups such as Greenpeace, the World Wildlife Fund and Friends of the Earth use transnational social, economic and cultural networks to politicize environmental issues and mobilize the global civic society, aiming not only to alter norms and practices leading to the shifting of standards coinciding with the ideals of these groups, but also to define political agendas and determine the design of decision-making processes. Pamela Chasek (2001) documents how civic society groups have shaped the course of various negotiations directly or indirectly when dealing with environmental issues.

Environmental activists have regularly used science to convince policy-makers of the need for policies to address the increasing problems posed by environmental threats (see Eyerman \& Jameson 1989; Fogel 2002; Epstein 2005). Environmental activists have identified the increase of public awareness as their main strategy to attract the attention of policy-makers (see Chasek 2006; Dong 2010). For example, activists have used the results of scientific studies, leading to their success in achieving the collective 1982 declaration of an international ban on commercial whaling (Aron 2001), ozone depletion (Litfin 1994), transboundary movements of hazardous wastes (Kempel 1993), and climate change (Andresen \& Gulbrandsen 2003). Currently, it seems unimaginable to exclude NGOs and other environmental groups from climate change negotiations, given the high degree of public interest in and concern for the issues involved (Depledge 2005).

Expanding environmental activism to other issues such as sustainable development and energy security is regarded as inevitable, due to the interlinkages of these three policy priorities (Mawhinney 2002; Hopwood et al. 2005a; Kalhauge et al. 2005; Jabareen 2006). Nevertheless, environmental activism needs to expand its existing networks to include those groups whose interests complement their own. New alliances may be formalized with "sustainable activism" (see Goldin \& Winters 1995; Fisher \& Green 2004; Berrueta et al. 2015) and "green energy activism" (see Fitzpatrick 2014; Mission Innovation 2015), which will require prior evaluation of new conflict cleavages among these groups.

When activists are able to hold positions in one of these cooperating agencies, they will be confronted with the need to learn to consider procedures to be equally as important as results. The hierarchies, management and bureaucracy of different agencies are often diverse as they are defined by institutional memories, where the "due process" as coordination requirements may take longer and will eventually increase the frustration of activists, paving the way for more motivation to circumvent these procedures. Fig. 8.3 depicts the transformation process with activists predominantly in the driver seat. 


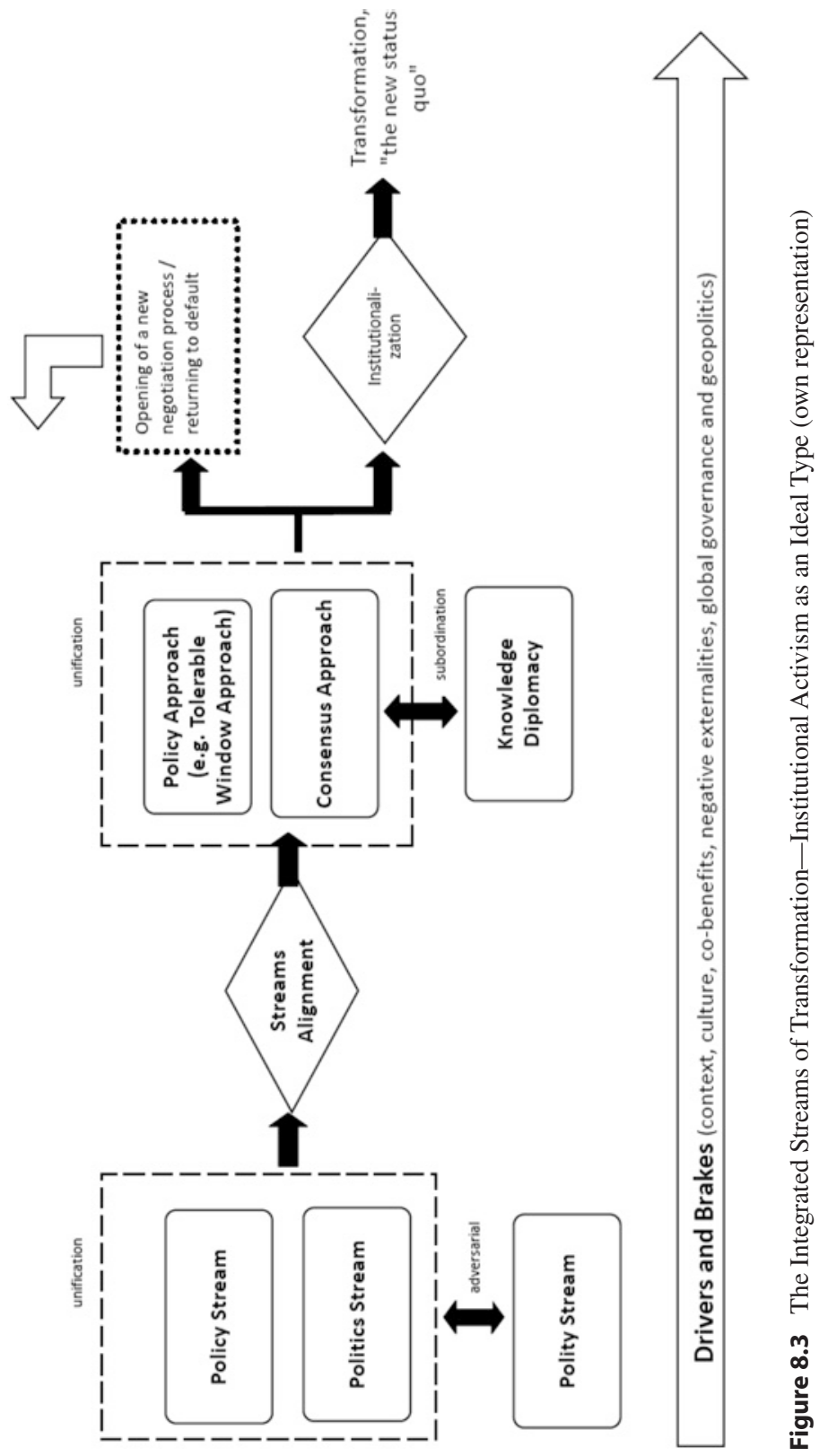


The ideal type of institutional activism in decision-making is summarized as follows:

\subsubsection{Context: Actors and Issues}

The ideal type of institutional activism involves activists who are either elected or appointed to government posts, and who are mandated to define and implement policy goals. Activists hired in management positions can also be considered to be "institutional activists" if they are able to "shift" government policies in the direction coinciding with the activists' advocacies by introducing game-changing measures or strategies.

The previous figure (Fig. 8.3) illustrates the union between the "policy" and the "politics stream." In the two first phases of negotiative transformation, the opening of the process and agenda-setting for the negotiation process are dominated by institutional activists. In this ideal type, polities such as legal frameworks and other bureaucracies can be perceived as adversarial to the policy and politics stream. Stream alignment is often implemented with less participation from other institutions.

The union of the policy and politics streams dominates the identification of relevant issues. Because specific issues are non-negotiable for institutional activists, these issues are less receptive to compromise and are often based on ideologies or normative belief systems. The union between the policy and consensus approaches, as a direct consequence of the union between the policies and politics stream, leads to definition of the role of knowledge as a subordinate position. Science ceases to become a partner and becomes arbitrary and merely an instrument for legitimacy purposes. While issues are often backed with scientific studies, when scientific studies are unable to support arguments or when these are adversarial to the activists' arguments, other sources of legitimacy or methods of discrediting policy-makers are sought, such as mass demonstrations or public naming, blaming and shaming.

\subsubsection{Agency: Structures and Processes}

Institutional activists, prior to their government position, often complained about the biased structures of decision-making, where powerful actors such as corporations and business groups are able to dominate the process because of the resources at their disposal. Policy spheres (e.g., mining policy) are often established by dominant actors. Because of the lack of formal channels to effectively 
express opposition within this "policy sphere", activists tend to rely on social networks to mobilize popular support as leverage. However, now that they are in power, institutional activists are ironically taking advantage of the lack of effective formal channels to express opposition to their own advantage. As such, formerly powerful actors now look for other frameworks outside the distinct policy sphere to oppose decisions, such as courts or even social networks.

The transformation process in this deviating policy regime tends to circumvent existing bureaucracies and procedures for the sake of efficiency and effectiveness. The transformation process is less likely to be consensus-based. Therefore, the system will witness the emergence of new conflicting and highly competitive processes. The rhetoric will most likely be aggressive in blaming opposing counterparts, and the possible outcomes will also most likely be perceived as negative-sum. Instead of looking at potential synergies between the interests of actors, strategies will revolve around how the other actors can be disenfranchised, discredited and excluded. Furthermore, the transformation process is understood as "linear", as short-term "set-backs" for the sake of long-term strategies are most likely unacceptable.

\subsubsection{Audience: Outcomes}

Results tend to be the only things that matter for institutional activism. The outcomes are most likely short-term, as there will most likely be challenges after the activists leave office. New elections tend to be perceived as disruptive, as they will most likely bring uncertainties and instability. When opposing parties win elections, emerging vacuums will most likely define the relations between actors. In addition, because the results achieved through institutional activism are often reached by ignoring existing procedures, they will be confronted by legal and other types of challenges. A high proportion of the resources of institutional activists will be needed to address opposition, which may effectively "wear out" activists, prompting them to seek more drastic measures. Therefore, the implementation of these results will be the major hurdles for the institutional activist. The lack of broader support for policies produced by institutional activists increases the costs of transformation. In addition, the outcomes concentrate more on issues, rather than changes in the "social contract" or the mechanisms and procedures of decision-making. Therefore, the outcomes will most likely fail to address existing, biased structures and will therefore produce or reinforce existing power asymmetries and inequalities, because the activists need these biased structures to produce the results they want. 
In this regard, while it is still possible for institutional activism to achieve transformation, it is a question of at which cost and at the expense of which actor. In addition, renegotiations of isolated terms or provisions are less likely, because of the highly competitive nature of the negotiation strategies used to achieve the results. New negotiation rounds, if they occur, will most likely encompass a default. Because of the high cost of renegotiations of terms, stalemates are most likely to occur, which may further delay important decisions to resolve problems.

\subsection{An Ideal Type of Transformation-The Technocratic/Bureaucratic Policy Pathway}

In policy-making in areas related to climate protection, sustainable development and energy security in particular, technocratic elements have become integral parts of decision-making structures and processes. While there is no concrete claim of being a purely 'technocratic' regime, current governments of both developed and developing countries as well as both democratic and authoritarian regimes have recognized the effectiveness of technocrats within their ranks (see McDonnell \& Valbruzzi 2014; Shelton \& Clark 2016; Rohde 2017). This section introduces an ideal type of a technocratic policy pathway. In addition, this section assumes that technocracy is reflected in the increasing importance of bureaucracies, where on the one hand, political decision-making is 'franchised' to technical experts and on the other hand, working groups such as scientific advisory councils have been tapped to assess problematic issues and to come up with solutions, and where politicians will most likely follow the 'recommendations' made by these 'expert committees.'

\subsubsection{Technocracy and Governance}

The academic debate about technocratic types of governance is becoming increasingly loud, particularly in policy discussions revolving around climate protection, sustainable development and energy security. The debate has evolved from its beginning and is now no longer concerned with technocracy in a classical or utopian sense where experts directly assume political power for the 'greater good.' The Platonic idea of philosopher-kings is often regarded as an early version of technocracy, in which the state is governed by those with expert knowledge of the 'good.' The 'technocratic narrative' has elevated the rule of the technocrats as one that has some problem-solving capacity and one that is linked with modernity (Shelton \& Clark 2016). 
Some academic scholars have coupled 'technocratic' qualification with profession or occupation. For example, the qualified minister of health is often regarded as someone who should have a medical background. There is then the question of how the evolution of a technocrat to a politician and vice-versa can be analyzed. When a medical doctor assumes the office of health minister, he or she needs to learn the challenges of bargaining interactions.

Technocracy can be found both in democratic and authoritarian regimes. As The Economist (2011) suggests, autocracy and technocracy are 'bedfellows', as authoritarian regimes prefer technocrats to run political offices. The Soviet Union is often classified as the first technocratic government. For instance, presidents of the Soviet Union often had a technical background in education. In addition, in 1986, 89 percent of Politburo members were engineers (Graham 1993 p. 74). As industrialization was promoted in the $1930 \mathrm{~s}$, engineers were rapidly promoted within the Communist Party. A similar development can also be observed in China. Similarly, military regimes often appoint civilian technocrats in government positions. Singapore and, to a lesser extent, Hong Kong, are often labelled as the 'best advertisement' for technocracy, where political and expert components of governance have merged completely, particularly through information technology (see The Economist 2011).

Several European democratic countries have seen the rise of technocrats as leaders, particularly in times of economic crisis. During political crises, technocrats are often the preferred 'compromise' candidate between competing political parties. Technocrats have, for example, assumed leadership during the financial crisis in Greece and Italy (see Grundle \& Parker 2012), as they were seen as able to rise "above the paralyzing political rancor" (Blair 2011). Two bureaucratsMario Monti, an economist, and Lucas Papademos, the former vice-president of the European Central Bank-were seen as the 'saviors' of these two countries. Technocrats are often preferred by markets and international partners over 'indecisive' Berufspolitiker (career politicians) as they are able to provide concerted answers that political figures are unable to give (see Blair 2011).

While technocratic principles have their own merits, unelected technocrats holding political positions are required to 'evolve' into politicians as time passes by. Jürgen Habermas (2013) in his book 'Im Sog der Technokratie' sees democracies with increased technocratic tendencies as weak democracies, as the elite is able to identify the quickest means to achieve their interests under the banner of efficiency. He continues to argue that technocratic governance structures are less receptive to persuasion and bargaining interactions. The European financial crisis has enforced technocratic principles and institutions in solving the crisis that many scholars argue was caused or at least promoted by technocrats, who failed 
to supervise financial institutions. In addition, Jürgen Habermas links the current 'political crises' of the European Union, including Brexit and the emergence of alt-right movements, to its technocratic tendencies.

Nevertheless, other academic scholars have argued that technocrats are primarily driven by their cognitive 'problem-solution mind-sets' (see Njalsson 2005), where relevant ideas and decisions are forged not or less by political ideologies, but by how information is assessed and interpreted. As such, technocrats are often regarded as being independent of lobbying. However, the absence of lobbying can also be 'undemocratic', as lobbying does not always need to refer to powerful business and industry groups influencing policy-making but can also refer to social movements and grass-root organizations aiming to persuade policy-makers.

Furthermore, as mentioned above, there is a need to clarify the idea that technocratic features can be observed in both democratic and authoritarian governments. While technocratic principles can be seen as undermining accountability in democratic countries, as these experts may not be elected through a popular vote, technical expertise can be a significant legitimizing factor in democracies, especially those experiencing a crisis. For example, the constitutional protection bestowed upon Central Banks and the judiciary to guarantee independence from political interference is an example of the technocratic characteristics of democratic political systems. Furthermore, in authoritarian states, technocratic principles can also be prevalent. With the practical absence of a popular election, technical expertise becomes a major criterion for recruitment to political offices (see The Economist 2011).

\subsubsection{An Ideal Type of Transformation-The Technocratic/ Bureaucratic Policy Pathway}

The following illustration (Fig. 8.4) summarizes the various processes of a technocratic policy pathway in the context of transformation. Decision-making is initiated solely or predominantly by expert committees, forming the union of the policy and polity streams. Other societal actors belonging to the politics stream have limited channels to influence decision-making, and in many cases their involvement is tolerated only in agenda-setting. Stream alignment is, as expected, rather simple and the agendas are not subject to external contestation. Solutions are reached through closed-door expert committee meetings and there is the connotation that whatever solutions are produced, these are for the sake of the common good (Fig. 8.4). 


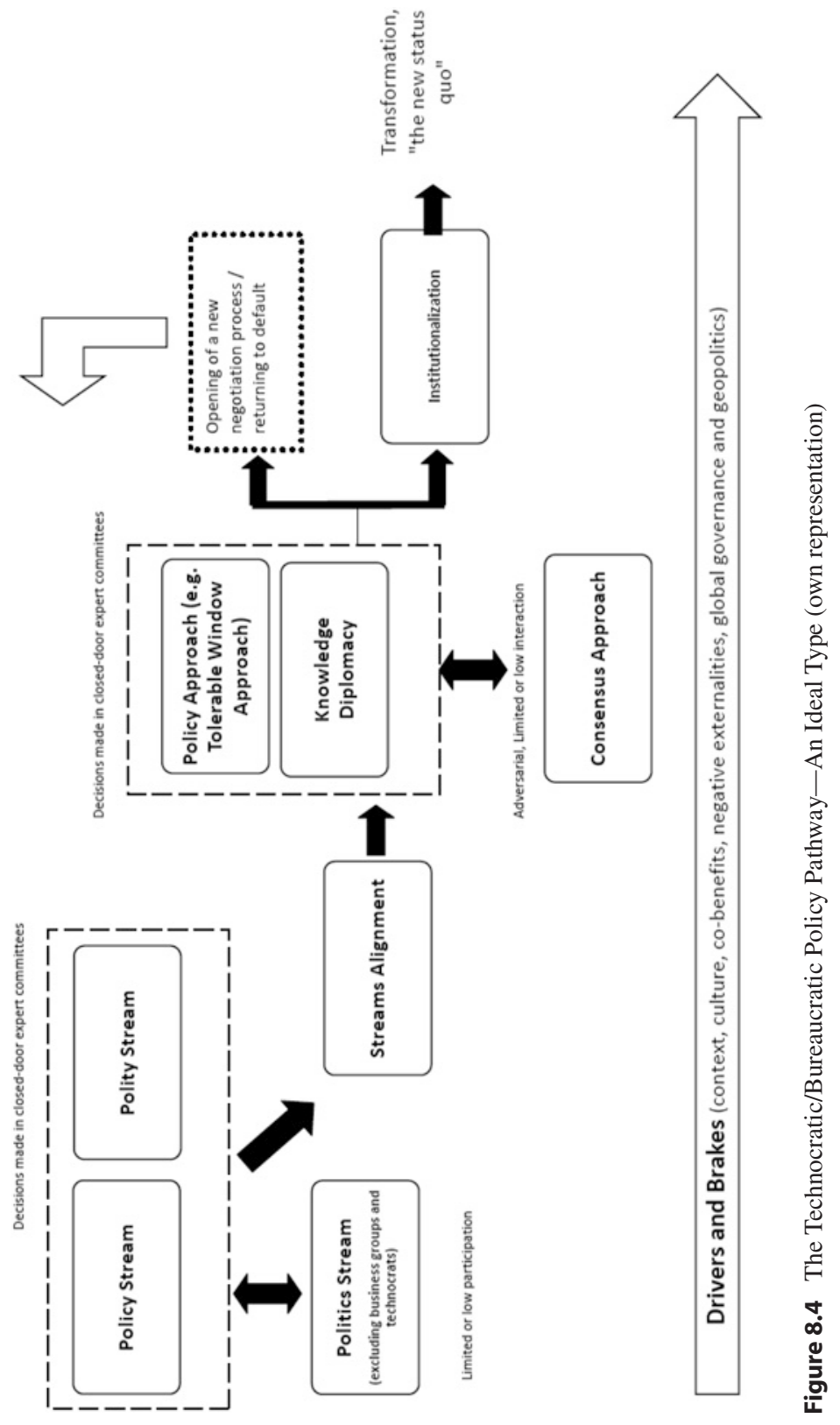




\subsubsection{Context: Actors and Issues}

An elected or appointed politician (e.g., president, prime minister, minister) is defined as a technocrat if he or she has, prior to his/her (first) appointment or election, never held public office under the banner of a political party or is not a formal member of any political party. A technocrat can also be someone who is elected through an electoral campaign that emphasized non-political, technical expertise (e.g., a businessperson, scientist, teacher or athlete). He or she can also be appointed upon recognition of non-political expertise that is directly relevant to the role occupied in government (e.g., a military general as minister for defense, a doctor as minister of health, or a lawyer as minister for justice) (see McDonnell \& Valbruzzi 2014).

A significant portion of the population is 'apolitical' if not defined by politically apathy. On the one hand, a technocracy can be the result of this increasing political apathy in the population. On the other hand, political apathy is reinforced by technocratic practices, with the public losing channels to influence policy-making. In addition, social movements that seek to influence the policy-making process will most likely employ 'technocrats' to represent them. Speaking the same language, NGOs that are able to manifest the same technical expertise will mostly likely be embedded in the decision-making process.

Relevant issues will most likely be identified, chosen for the agenda, and addressed by technocrats both from the policy and polity streams. The politics stream assumes a merely 'responding' or 'recipient' role. The assessment of the issues will very likely be conducted using presumed technical methodologies that are systematic and perceived to be representative. Conflicts evolving from these issues are seen as a matter of differences in methodologies and in the calibration of models and projections. Furthermore, issues tend to be de-politicized and are often not subjected to political debate, at least not the methodologies. There is an understanding that isolating these issues from the political sphere serves the interest of the public, particularly in times of crises.

\subsubsection{Agency: Structures and Processes}

Technocratic characteristics of decision-making are reflected in the structural design of governance. At first glance, the technocratic policy pathway will be highly dependent on institutions. The 'proliferation' of institutions will most likely imply a huge bureaucratic system. Institutions are most likely independent from each other, implying dispersed decision-making. Nevertheless, because of 
the highly formalized nature of governance, institutions will most likely be skeptical of engagement in new policy areas. Because interactions between institutions are also highly formalized, bargaining interactions are shifted towards back-channel communications. In addition, bargaining interactions with non-expert social groups are limited. In addition, the intersections or cross-cutting features of policy areas will require additional institutional mechanisms. Paradoxically, while technocrats can find quick answers to problems in the short term, in the long-term technocrats will most likely accumulate the control over procedures and structures to promote the efficiency of the system leading to a 'fat' bureaucracy.

A technocratic policy pathway will most likely imply a high level of social capital in the short term, as the public will tend to tolerate a lack of inclusiveness and transparency for the sake of technical effectiveness. Nevertheless, additional legitimizing actions will be needed as this tolerance tends to be short-term and challenges will be voiced in the long-run as the ramifications of policies move from the collective to the personal level. Without such additional legitimacy, the public will 'feel' the distance between decisions and society. The technocratic 'establishment' will then be highly criticized as 'undemocratic.' Institutional interactions are highly formally defined, with clear jurisdictions and mandates of government agencies. Unlike the situation in many democratic regimes, there is no or very low competition between government agencies.

Communication channels tend to be one-way with the technocratic regime merely informing the public about the benefits of decisions that it has made. Persuasion and bargaining interactions tend to be highly formalized. Technocratic policy pathways are also characterized by 'dispersed decision-making' as a result of the dynamics of factional politics (see Gilley 2012), as decisions are most likely 'bundled' according to the 'expert committees' formed. For example, as health issues will be addressed by health experts, there is a tendency that experts on energy will not be invited to the health committee. As such, additional processes are needed to structure functional interactions between 'policy issue groups.'

There is limited or low interaction with other societal actors in terms of assessing the ramifications of the solutions proposed. Knowledge diplomacy occurs solely within expert committees. At one point, these solutions will be implemented and institutionalized, leading to the new status quo and thus completing the transformation process. Due to the exclusion of some stakeholders who will be affected by such decisions, the regime will need additional resources to ensure that these solutions will not be challenged. For some regimes, additional legitimacy will be derived through output legitimacy (performance) or through international recognition of their 'efficient' structures. For others, the legitimacy of unelected technocrats is achieved through plebiscites or active informa- 
tion campaigns to gain popular support. Other governments resort to 'quiet' approaches, where solutions are not 'loudly' announced through the media.

\subsubsection{Audience: Outcomes}

The results of expert committee decisions are 'dispersed' and highly 'factional.' Therefore, outcomes of committee deliberations in a technocratic policy pathway will tend not to be integrative. As there is most likely no competition among government institutions and agencies with clear jurisdictions and mandates, additional measures are most likely needed to make sure that the 'technical' decisions made are cohesive. The proximity of decisions made by technocrats to the 'sentiments' of certain members of the society will most likely lead to the rise of anti-intellectualism.

\subsection{An Ideal Type of Transformation-The Post- Democratic Policy Pathway}

As an ideal type, a post-democratic policy pathway is not a 'continuation' or a later version of a democratic pathway. Rather, it is a policy pathway that is democratic in nature but has some features that are typical of pre-democratic political systems (see Crouch 2008). In this ideal type, the role of the finance, business and industry sectors refers not only to the involvement of the representatives from these sectors in the policy-making processes either as direct appointees or elected officials, but also to the installment of market-based principles and a logic in the narratives that legitimizes political actions. The emphasis on money and economic values in the political goals of policy-makers is a significant deviation from a democratic policy pathway, where social, political, cultural, economic and environmental interests are of the same rank. As a deviation, there is a need to conceptualize how post-democratic characteristics shift institutional, functional, and bargaining interactions in the context of a transformation towards sustainability.

Although there are similarities, post-democratic policy a pathway is differentiated from a technocratic pathway. While a technocratic policy pathway pertains to an emphasis on knowledge-based decision-making through technical experts, which may also include financial experts, a post-democratic policy pathway solely or dominantly employs experts from the financial, business and industry sectors. These 'money' experts are directly or indirectly mandated to make decisions relevant to non-economic issues. 


\subsubsection{Post-Democracy and Institutional Interactions}

Post-democracy is a concept that has emerged from protest movements. As the European financial and economic crisis of 2008/2009 unfolded, there was criticism of how current democratic systems have shifted away from the 'ideals' of democracy. Post-democracy is labelled as 'unhealthy' democracy, where indicators of pre-democratic eras can be recognized without moving back to these times. Colin Crouch (2008 p. 13) argues that while democratic institutions are still formally unimpaired, political procedures and governments increasingly manifest structures typical of pre-democratic times. One of these developments refers to the retraction of democratic participatory requirements and the replacement of these requirements with outputs and performance. The discrepancy between the formal democratic legitimacy models of governance and the political actions increasingly legitimized through efficiency distorts democratic procedures.

The 2008-2010, the economic and financial crisis in Europe led to new discussions about institutional deficits in the European economic and financial system (see Sell, Friedrich, L. \& Sauer 2011; Ullbrich \& Lipponer 2011). Most authors see the economic and financial crisis in 'small boxes', and often ignore the 'spill-overs' between different policy domains. The analysis of institutional interactions occurring between political actors (such as ministers, members of the parliament and bureaucrats) and banks as well as the financial service sector has led to insights into how democratic principles have been changed or re-defined. Particularly because the state is regarded as the guarantor of economic stability, deriving its output legitimacy through the level of its economic welfare, the question arises as to whether the same state can act as 'referee' in the society, where social welfare or even climate protection can be undermined by the primacy of economic welfare.

Post-democracy is a political science concept that aims to explain how certain societal actors are extruded through the dominance of economic actors that leads to the establishment of state structures that favor money interests and focus on economic values. For example, the erosion of state monitoring and verification mechanisms in a post-democratic state is a consequence of the typical devolution of state functions to private actors, particularly because 'privatization' tends to be equated with rationalization and efficiency. This development is regarded as being a feature of post-democracy, which often leads to a legitimacy crisis. Armin Schäfer (2008) argues that trust in the capability of the state decreases, particularly because the privileges given to these economic actors are often translated into a decrease of social welfare. 
The following illustration summarizes the interactions of the different streams as well as the processes leading to the achievement of the transformation (Fig. 8.5).

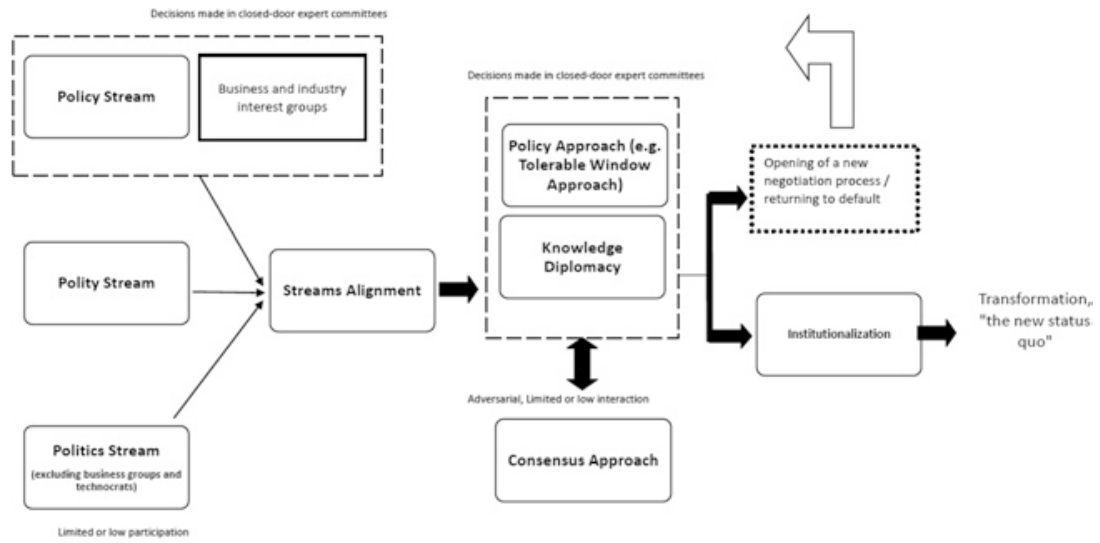

Drivers and Brakes (context, culture, co-benefits, negative externalities, global governance and geopolitics)

Figure 8.5 The post-democratic policy pathway—an Ideal Type (own representation)

\subsubsection{Context: Actors and Issues}

In this ideal type of policy pathway, representatives or proponents of the finance, business and industry sectors have been able to establish themselves in the policy stream. As various financial actors such as the 'rating agency' Moody's are able to use the threats of lowering the solvency ratings of countries to compel political actions, governments are most likely to assume the socio-technical and socio-linguistic narratives of these agencies when legitimizing unpopular austerity measures and other market instruments such as cuts to subsidies to the coal energy sector. Particularly in a post-democratic state, governments have become highly dependent on loans and investment from the private sector. With a negative rating, governments will find it difficult to access loans with acceptable terms. Moreover, particularly in times of economic hardships involving deficit-tainted governments forced to bail out financial institutions and business or industry companies that are too big to fail, austerity measures are expected to be implemented to prevent 
further negative ratings. These austerity measures tend to limit expenses relating to social welfare, further vindicating the dominance of economic actors.

A further characteristic of a post-democratic ideal type refers the state ceasing to be the sole holder of monopoly of authority and welfare services, as it has privatized most of its functions. The state will most likely be concentrating on the bureaucracy (polity stream). As the state has privatized most of its functions, policies are now in the hands of the 'private sector.' As 'bidding' for the state functions were conducted in an 'auction' like process, economic actors would have eventually won the biddings. Through the dominance of 'money actors' in policy-making, the state will most likely assume 'money logic' in constituting the 'rules of the game' in the bargaining space. As a consequence of privatization, the state will be de facto substituted by the private sector, similar to how the Medicis controlled politics in Florence in the $15^{\text {th }}$ century. As dominated by the private sector, the state ceases to be the genuine regulator, becoming a player itself and leading to further legitimacy crises due to the bias favoring the interests of 'money actors.'

A major characteristic of a post-democratic policy pathway is the reduction of the functionality of the State to being merely a 'security instrument' through diverse waves of privatization. Indeed, in some countries, even security services have been outsourced to private security companies. As such, a further reduction of the quality of democracy is implied, as diminished transparency and unclear accountability are to be expected (see Crouch 2008). Nevertheless, not all sectors of social life can be privatized. The state will need to take over sectors that cannot yield profits and which no business company is willing to take. This will most likely lead to a further erosion of the quality of government services as the 'poor', without a political voice, will be the only remaining direct 'dependents' of the state (see Hirschmann 1974; Crouch 2008). Following 'market logic,' government expenses for the poor-who are considered the 'others' — will be eventually reduced over time as these will most likely not yield profits.

Due to the perceived bias of the state, other societal actors (politics stream) will most likely be motivated to seek alternative channels outside state mechanisms. While a significant portion of the population will resort to resignation and political apathy, others will mostly likely be motivated to use paralegal instruments. As such, societal actors will most likely be perceived and will understand themselves as part of 'protest movements', stirring further political apathy in the population. Issues and agendas for policy-making will be primarily determined through economic lobbyism. Because of the access of economic elites to political power, political authority lies de facto on the table of the CEOs and directors of financial and economic institutions and actors. The lobbyism of economic actors 
in post-democratic policy pathways is highly effective, because economic elites can threaten governments with the idea that policies limiting the activities of economic actors will lead to a reduction of employment. In addition, most economic actors see lobbyism as an investment, which promises revenues in the future. This is part of the logic that investment should only be done in areas where profits can be expected, and no longer in areas that serve common good.

Issues will most likely entail 'horror scenarios' should governments fail to effectively address emerging issues. The importance of actors that are specialized in developing such horror scenarios, such as rating agencies and, to a lesser degree, industry associations, will most likely be reinforced in post-democratic policy pathways. Non-economic issues such as animal protection and human rights protection will often be secondary in government decisions. Economic sanctions on countries that regularly and systematically violate human rights will be harder to legitimize and implement. As such, proponents of these non-economic issues will need to find ways to couple these issues with existing economic interests. They will need to speak the language of 'money actors,' and employ the same methodologies, further reinforcing the dominance of market logic in the society.

\subsubsection{Agency: Structures and Processes}

Decision-making in post-democratic pathways are highly dependent on structures such as institutions and bureaucracies. The polity stream complements the policy stream in framing the agenda for further interactions. Nevertheless, in contrast to technocratic pathways, jurisdictions and mandates of individual institutions are not fully clear and there is a market logic preventing the clear separation of powers. As the market logic implies the necessity of 'healthy' competition among state institutions, institutional interactions will be limited. Due to the privatization of most of the public services of the state, the state will most likely have low autonomy and low capacity. As it is merely functioning as a regulatory body, should the government initiate and pursue more ambitious targets it would need more assistance and collaboration from other actors such as the finance, business, and industry sectors. The success of government-led programs will be highly dependent on how the economic actors will think they will profit from these programs.

Streams alignment will be more likely structured using practices typically used in the finance, business and industry sector. For example, issues that promise the most economic value will be prioritized over the others that are merely of 
'symbolic' importance. In addition, the methodologies that will be used to assess the feasibility of political actions will most likely use monetary, cost-benefit analyses. The tolerable window approach will be de-politicized and commercialized. What is acceptable is what brings economic value compared to costs. Maximizing benefits with the lowest possible costs will frame political actions. Structures that regulate the actions of all stakeholders will be stable, primarily because adhering to these rules and regulations will bring more value and not because of equity concerns. Cost-benefit calculations will define the effectiveness of structures in managing functional interactions. In addition, serving as a basis or criteria for rationality, cost-benefit analytical methods will further reinforce the privatization or commercialization of public services and welfare. At some point, cost-benefit thinking will define equity as it penetrates all sectors of social life. Bargaining interactions in a post-democratic policy pathway follow the market-driven and market-defined frameworks for assessing the feasibility of policies. Consensus-building is exclusive to only the economic value of decisions. Knowledge plays a significant role merely in providing inputs on costs and benefits as well as risks and opportunities.

Policy-makers in a post-democratic policy pathway will most likely follow the approach of 'system relevance' or 'too big to fail.' Government bail-out programs using tax-payers' money to the finance, business and industry actors will depend on how their failure to do so would have fatal consequences for the stability of the financial system and the economy. As such, post-democratic pathways will most likely require additional legitimizing mechanisms, particularly when profits are privatized while risks and losses are socialized. Furthermore, the 'system relevance' approach will most likely distort bargaining interactions, because actors such as labor unions and welfare associations, which do not enjoy the status of system relevance, will be confronted with an unfair bargaining sphere.

Of equally importance is how the concentration of power within the inner ellipsis in the context of a 'low intensity democracy' (Kreisky 2002 p. 60) will promote the further personalization of politics. Political communication will focus more on the people involved as the proximity between the electorates and governance structures increases. A further implication involves the increased importance of communication channels, such as conventional media and social media, in producing 'positive', image-building material relating to the policies and people behind policy-making. Problematic issues will most likely be solved not by looking at the root causes of the problems but through strategic PR activities. Because governments will be more inclined to keep a positive image, they will most likely want to control more of these communication channels, further 
reinforcing transparency deficits. For example, the highlights of closed-door meetings and conferences will no longer be the exchanges of ideas and bargaining interactions, but will tend to be the press conferences (Guehenno 1994).

\subsubsection{Audience: Outcomes}

Decisions and policies will be less likely the results of bargaining and persuasion involving all relevant stakeholders. Moreover, policies will not be developed through compromises and collaboration with societal groups but will rather be predominantly achieved through direct and indirect interactions between government officials and representatives of the finance, business and industry sectors.

Moreover, the privatization of major state services will on the one hand lead to dispersed decision-making. On the other hand, outsourcing state services also means that governments will simultaneously rely heavily on consultants and experts (see Crouch 2008). Dispersed decision-making and factional politics will be complemented by a centralized concentration of power to the inner ellipsis of decision-makers, further reinforcing transparency deficits.

As the development and implementation of policies in the transformation process are exclusive, the outcomes of various bargaining, institutional and functional interactions will be mostly fragile in terms of input legitimacy. Nevertheless, as an implication of the assumption of market logic as an indicator of the efficiency of performance, the relevance of output legitimacy will surpass that of input legitimacy.

Outcomes will be confronted with social distrust. The tendency of governments to rely heavily on positive image-building ('branding') is counterproductive to promoting social trust. In addition, the political apathy of a significant part of the population will be reinforced by governments' increased control of the media, with critical voices easily labelled as enemies of the state.

\subsection{Interim Conclusion}

The usage of the ideal types as theoretical models of policy-making can be useful in analyzing current irritations resulting from contradicting processes. While ideal types represent the "ideals" of selected policy regimes, the analysis of the reasons behind deviations in real-life regimes can provide important inputs to allow a more grass-roots understanding of decision-making. A comparison between the ideal types and the real-life policy models can identify the 'corridors' in which 
transformation can occur. The ideal types uncover the potentials of connecting policies with the assumptions made in the previous chapters. For example, it could be the case that policy-makers in democratic regimes are generally inclined to consult civil society groups. However, the same policy-makers may then prefer to exclude civil society groups, for example, from foreign policies or from climate mitigation policies. The attention of the analysis can be directed towards understanding how this change of preference arises. For example, these policy-makers may have learned from their own personal experience that civil society groups may be highly competitive when it comes to climate mitigation projects.

In addition, because some experts argue that authoritative or semi-authoritarian governments are also capable or even more capable of achieving success in climate protection projects (see Schreurs 2011), some policy-makers in democratic countries (referred to as "eco-authoritarians") are currently more willing to "sacrifice" inclusion (as a democratic principle) and other democratic principles for the sake of efficiency, especially when accountancy is increasingly measured by the formal success of economic development plans and external security (see Hardin 1968; Heilbroner 1974; Porritt 1984). Nevertheless, other experts argue that some authoritarian or semi-authoritarian states can only 'tolerate' environmental activism as long as its advocacy is not directed at governmental agencies.

Open Access This chapter is licensed under the terms of the Creative Commons Attribution 4.0 International License (http://creativecommons.org/licenses/by/4.0/), which permits use, sharing, adaptation, distribution and reproduction in any medium or format, as long as you give appropriate credit to the original author(s) and the source, provide a link to the Creative Commons license and indicate if changes were made.

The images or other third party material in this chapter are included in the chapter's Creative Commons license, unless indicated otherwise in a credit line to the material. If material is not included in the chapter's Creative Commons license and your intended use is not permitted by statutory regulation or exceeds the permitted use, you will need to obtain permission directly from the copyright holder.

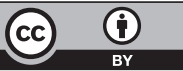

